\title{
CAMBRIDGE
}

\section{Richard Strauss}

Man, Musician, Enigma

Michael Kennedy

Written by Michael Kennedy, music critic for the Sunday Telegraph, this first detailed biography of Richard Strauss for many years re-assesses the man and the musician, drawing on much hitherto ignored material. In particular it considers Strauss's position during the period of the Third Reich.

'Written in an elegantly accessible style, this is the most valuable book on Strauss and his music to have appeared in English.'

Charles Osborne, BBCMusic Magazine

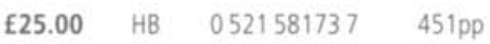

\section{Opera in History}

From Monteverdi to Cage

Herbert Lindenberger

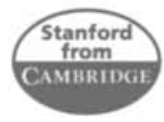

Examining the achievements of composers such as Monteverdi, Handel, Rossini, Wagner and John Cage, Lindenberger looks at how the operatic canon has been reshaped at key moments in its history. At a time of increasing interest in opera, he examines some crucial issues that run through its history

$\begin{array}{llll}\mathbf{f 3 5 . 0 0} & \text { HB } & 0804731047 & \text { 378pp } \\ \mathbf{f 1 2 . 9 5} & \text { PB } & 0804731055 & \end{array}$

\section{Vincenzo Bellini: Norma}

David Kimbell

Norma is by common consent the finest of the ten operas composed during Vincenzo Bellini's short career. Professor Kimbell provides the biographical and çultural context of the opera, examines its artistic qualities and suggests something of the impression Norma has made since it was first produced.

$\begin{array}{llll}\mathbf{f 3 5 . 0 0} & \text { HB } & 0521480361 & \text { 155pp } \\ \mathbf{f 1 2 . 9 5} & \text { PB } & 0521485142 & \end{array}$

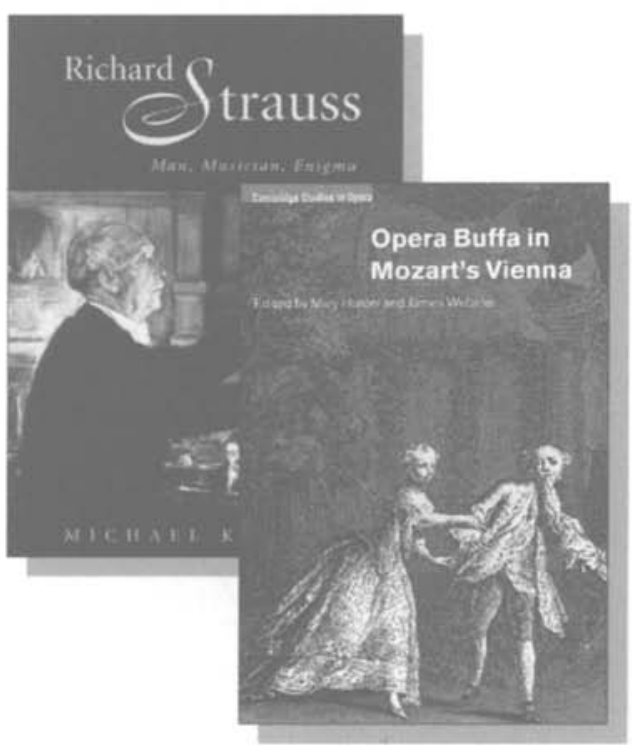

\section{Opera Buffa in Mozart's Vienna}

Mary Hunter and James Webster

Explores the world of Vienna and the development of opera buffa in the second half of the eighteenth century. Among the topics examined are Mozart and eighteenth-century comedy; gender, nature and bourgeois society on Mozart's buffa stage; as well as close analyses of key works such as Don Giovanni and Figaro. ‘... an enthralling collection of essays by a distinguished group of international scholars ... will give any reader a deeper knowledge and understanding of Mozart's comic operas and of the genius who created them.'

Scenaria
$£ 45.00$
HB
0521572398
$471 p p$

Stanford University Press books are distributed by Cambridge University Press

Cambridge books are available from good bookshops, alternatively phone UK $+44(0) 1223325588$ to order direct using your credit card, or fax UK +44 (0) 1223325152 . 


\section{GUIDELINES FOR CONTRIBUTORS}

Contributions may be sent to the editor:

\section{Professor Mary Hunter}

Music Department, 9200 College Station, Bowdoin College, Brunswick, ME 04011, USA

The return of contributions cannot be guaranteed unless return postage is provided.

Essays should normally be no more than about 18,000 words in length. 10,000 words is a normal lower limit, though exceprions can be considered if the subject matter warrants it. Authors should indicate the word count with the original submission.

When an article has been accepted for publication, the author is strongly encouraged to send a copy of the final version on computer disk (Apple Macintosh or IBM compatible PC) togetber with the hard copy typescript, giving details of the wordprocessing software used (Microsoft Word or Word Perfect). However, the publisher reserves the right to typeset material by conventional means if an author's disk proves unsatisfactory.

Manuscripts should be double spaced throughout (including footnotes, etc.) and should be typed on one side of the paper with ample margins. Contributors with word processors are requested to underline rather than use an italic font, and to avoid justification of right margins, automatic hyphenation and bold face type. Authors should send a brief (one-paragraph) biography with the final copy of the manuscript.

Footnotes should be numbered consecutively and be typed, double spaced, on separate pages at the end. Musical examples, figures, tables, etc. should be supplied on separate sheets.

Contributors who wish to reproduce photographs should provide good black and white prints, full details of the source and the full address of the copyright holder if this differs. Photographs will not normally be considered unless they are an intrinsic part of the contribution, and their inclusion will always be at the discretion of the editors. Contributors are responsible for obtaining permission to reproduce any material in which they do not hold copyright and for ensuring that the appropriate acknowledgments are included in their typescript. The full address of the copyright holder should be provided.

Punctuation should follow standard British practice. Single quotation marks should be used with double reserved for quotations within quotations. Punctuation that is not part of the quoted material should be outside closing quotation marks, as should footnote indicators. Longer quotation should be indented left without quotation marks and double spaced. Prose citations should be in English unless the original is of particular importance, unpublished or inaccessible, in which case the original should be followed by a translation in square brackets. Verse citations should be in the original language followed by a prose translation in square brackets.

Dates should be on the following model: c. 1740, 1840s, 5 February 1943. References should be to: Act I scene 2, op. 1 no. 2 in E major, Ex. 12 and Exx. 12-14, Fig. 3 and Figs. 6-9, motif(s) and leitmotif(s). For precise identification of pitch, use this system.

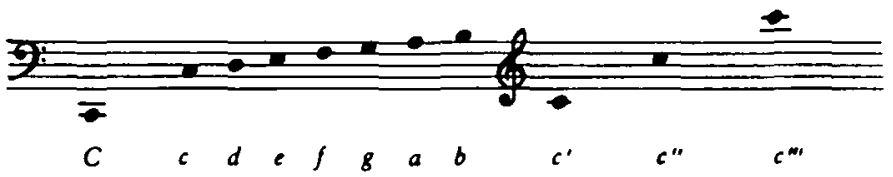

Sample footnotes (do not abbreviate journal titles):

${ }^{1}$ John Whenham, Claudio Monteverdi: 'Orfeo', Cambridge Opera Handbooks, 3rd edn (Cambridge, 1996), 44-6.

${ }^{2}$ Gerald Abraham, ed., The Age of Beethoven, 1790-1830, New Oxford History of Music, 8 (Oxford, 1982), 100-6.

${ }^{3}$ Curt von Westernhagen, Wagner: A Biograpby, trans. Mary Whittall, 2 vols. (Cambridge, 1978), II, $77 \mathrm{f}$.

${ }^{4}$ Winton Dean, 'French Opera', in Abraham, Beethoven, 137-46.

${ }^{5}$ Emest Newman, The Life of Ricbard Wagner, IV (1947; rpt. New York, 1981), 212-15.

${ }^{6}$ Edgar Istel, 'Beethoven's Leonora and Fidelio', Musical Quarterly, 7 (1921), 228-31.

${ }^{7}$ K. T. Rohrer, "'The Energy of English Words": A Linguistic Approach to Henry Purcell's Method of Setting Texts', Ph.D. diss. (Princeton University, 1980), 33.

${ }^{8}$ Rohrer, $249 \mathrm{n} 3$.

${ }^{9}$ Whenham (see n. 1), 57.

First proofs may be read and corrected by contributors provided that they can give the editors an address through which they can be reached without delay and are able to return the corrected proofs, by airmail where necessary, within three days of receipt. 


\section{New from Princeton}

\section{The Culture of Opera Buffa in Mozart's Vienna}

A Poetics of Entertainment

\section{Mary Hunter}

\section{Opera Buffa} in Mozait's

Vienua

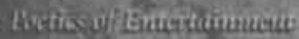

Mary Jfunter

\section{Metaphysical

Mozart's comic operas are among the masterworks of Western civilization, and yet the musical environment in which Mozart and his librettist Lorenzo da Ponte wrote these now-popular operas has received little critical attention. In this richly detailed book, Mary Hunter offers a sweeping, synthetic view of opera buffa in the lively theatrical world of late-eighteenth-century Vienna.

"In this wide-ranging, synthetic study Hunter ... constructs a poetics that integrates detailed and intelligent formal analysis into the social, cultural, and political issues of Josephine Vienna."

-Thomas A. Bauman, Northwestern University

Princeton Studies in Opera

Cloth $\$ 45.00$ ISBN 0-691-05812-1

\section{Metaphysical Song}

An Essay on Opera

\section{Gary Tomlinson}

In this bold recasting of operatic history, Gary Tomlinson connects opera to shifting visions of metaphysics and selfhood across the last four hundred years. The operatic voice, he maintains, has always acted to open invisible, supersensible realms to the perceptions of its listeners. In doing so, it has articulated changing relations between the self and metaphysics. Tomlinson examines these relations as they have been described by philosophers and shows how opera has brought these changing relations to the stage.

"This extraordinary book offers us an 'alternative story' of the history of opera. ... [It] will have an important ... effect on the way we think about opera."

-Roger Parker, Oxford University

Princeton Studies in Opera

Paper \$18.95 ISBN 0-691-00409-9 Cloth \$49.50 ISBN 0-691-00408-0

\section{Princeton University Press}

FROM BOOKSELLLES OR PHONE (1-243) 779777 U.K. • (800) 777.4726 U.S. HTTP://PUP.PRINCETON.EDU 